\title{
Dupilumab improves lung function in patients with uncontrolled, moderate-to-severe asthma
}

\author{
Mario Castro ${ }^{1}$, Klaus F. Rabe ${ }^{2}$, Jonathan Corren ${ }^{3}$, Ian D. Pavord ${ }^{4}$, \\ Constance H. Katelaris ${ }^{5,6}$, Yuji Tohda7, Bingzhi Zhang ${ }^{8}$, Megan S. Rice9, \\ Jaman Maroni ${ }^{10}$, Paul Rowe ${ }^{8}$, Gianluca Pirozzi ${ }^{8}$, Nikhil Amin $^{10}$, \\ Marcella Ruddy ${ }^{10}$, Bolanle Akinlade ${ }^{10}$, Neil M.H. Graham ${ }^{10}$ and Ariel Teper ${ }^{8}$
}

\section{ABSTRACT}

Background: Dupilumab, a fully human monoclonal antibody, blocks the shared receptor component for interleukin- 4 and interleukin-13, key drivers of type 2 inflammation. In the phase 3 LIBERTY ASTHMA QUEST trial (NCT02414854) in patients with uncontrolled, moderate-to-severe asthma, add-on dupilumab $200 \mathrm{mg}$ or $300 \mathrm{mg}$ every 2 weeks reduced exacerbations and improved forced expiratory volume in $1 \mathrm{~s}\left(\mathrm{FEV}_{1}\right)$ and quality of life over 52 weeks. This analysis evaluates dupilimab's effect on lung function in the overall population, and subgroups with baseline elevated type 2 inflammatory biomarkers.

Methods: Patients were randomised to 52 weeks of subcutaneous dupilumab $200 \mathrm{mg}$ every 2 weeks, $300 \mathrm{mg}$ every 2 weeks, or matched-volume placebos. Lung function outcomes were analysed in the overall population, in patients with $\geqslant 150$ eosinophils $\mu \mathrm{L}^{-1}, \geqslant 300$ eosinophils $\mu \mathrm{L}^{-1}, \geqslant 25 \mathrm{ppb}$ fractional exhaled nitric oxide $\left(F_{\mathrm{eNO}}\right)$, and both $\geqslant 150$ eosinophils $\mu \mathrm{L}^{-1}$ and $\geqslant 25 \mathrm{ppb} F_{\mathrm{eNO}}$, at baseline.

Results: Dupilumab treatment (200 mg and $300 \mathrm{mg}$ every 2 weeks) resulted in significant improvements versus placebo after 52 weeks in pre-bronchodilator $\mathrm{FEV}_{1}(0.20$ and $0.13 \mathrm{~L}$, respectively, versus placebo) and postbronchodilator $\mathrm{FEV}_{1}$ (0.19 and $0.13 \mathrm{~L}$, respectively), forced vital capacity (FVC) $(0.20$ and $0.14 \mathrm{~L}$, respectively), forced expiratory flow $\left(0.19\right.$ and $0.13 \mathrm{~L} \cdot \mathrm{s}^{-1}$, respectively) and pre-bronchodilator $\mathrm{FEV}_{1} / \mathrm{FVC}$ ratio $(1.75 \%$ and $1.61 \%$, respectively) in the overall population $(\mathrm{p}<0.001)$. Difference versus placebo in post-bronchodilator $\mathrm{FEV}_{1}$ slope of change (weeks $4-52)$ was significant $\left(0.04 \mathrm{~L} \cdot \mathrm{year}^{-1}\right.$; $\left.\mathrm{p}<0.05\right)$. Greater improvements were achieved in patients with elevated baseline blood eosinophil and/or $F_{\mathrm{eNO}}$ levels for most outcomes.

Conclusions: Dupilumab improves lung function outcomes, including large and small airway measurements and fixed airway obstruction, in patients with uncontrolled, moderate-to-severe asthma; particularly in patients with elevated biomarkers of type 2 inflammation.

@ERSpublications

Dupilumab is a fully human monoclonal antibody that blocks the shared receptor component for interleukin-4 and interleukin-13, key drivers of type 2 inflammation, improving lung function outcomes in patients with uncontrolled, moderate-to-severe asthma http://bit.ly/ 2OhKMpi

Cite this article as: Castro M, Rabe KF, Corren J, et al. Dupilumab improves lung function in patients with uncontrolled, moderate-to-severe asthma. ERJ Open Res 2020; 6: 00204-2019 [https://doi.org/10.1183/23120541.00204-2019].

This article has supplementary material available from openres.ersjournals.com.

This study is registered at www.clinicaltrials.gov with identifier number NCT02414854. Qualified researchers may request access to patient-level data and related study documents including the clinical study report, study protocol with any amendments, blank case report form, statistical analysis plan and dataset specifications. Patient-level data will be anonymised and study documents will be redacted to protect the privacy of our trial participants. Further details on Sanofi's data sharing criteria, eligible studies and process for requesting access can be found at www. clinicalstudydatarequest.com.

Received: 15 Aug 2019 | Accepted after revision: 13 Nov 2019

Copyright $\odot$ ERS 2020. This article is open access and distributed under the terms of the Creative Commons Attribution Non-Commercial Licence 4.0. 


\section{Introduction}

A high proportion of asthma patients (23-56.5\%) remain uncontrolled despite receiving maximum standard-of-care controller treatment. These patients suffer a significant ongoing disease burden, with poor health-related quality of life and increased risk of developing asthma exacerbations and accelerated decline in lung function [1-6].

Poor lung function as measured by forced expiratory volume in $1 \mathrm{~s}\left(\mathrm{FEV}_{1}\right)$ is a predictor of risk of asthma exacerbations [7] independent of symptom levels, and all-cause, pulmonary and cardiovascular mortality. Effective new treatments are required to improve lung function for patients with uncontrolled, moderate-to-severe disease.

Asthma is a heterogeneous disease, and type 2 inflammation driven by inflammatory cytokines such as interleukin (IL)-4, IL-5 and IL-13 plays a critical role in $>50 \%$ of patients with moderate-to-severe asthma $[8,9]$. Biomarkers such as blood and sputum eosinophil levels and fractional exhaled nitric oxide $\left(F_{\mathrm{eNO}}\right)$ are associated with type 2 inflammation [10] and useful for inflammatory phenotyping, which may help guide treatment [11].

Dupilumab, a fully human VelocImmune-derived $[12,13]$ monoclonal antibody, blocks the shared receptor component for IL-4 and IL-13, thus inhibiting signalling of both IL-4 and IL-13, cytokines implicated in numerous type 2 inflammatory and allergic diseases including asthma, chronic rhinosinusitis with nasal polyps (CRSwNP), atopic dermatitis and eosinophilic oesophagitis [14].

Dupilumab is approved by the US Food and Drug Administration [15] as an add-on maintenance treatment in patients with moderate-to-severe asthma aged $\geqslant 12$ years with an eosinophilic phenotype or oral corticosteroid-dependent asthma; in Japan by the Pharmaceuticals and Medical Devices Agency for patients aged $\geqslant 12$ years with severe or refractory asthma whose symptoms are inadequately controlled with existing therapy [16]; and by the European Medicines Agency [17] as an add-on maintenance treatment in patients aged $\geqslant 12$ years with type 2 severe asthma characterised by increased blood eosinophils and/or raised $F_{\text {eNO }}$ inadequately controlled with high-dose inhaled corticosteroids (ICS) plus another medicinal product for maintenance treatment [18-20]. In addition, dupilumab is approved in the USA as an add-on maintenance treatment in adult patients with inadequately controlled CRSwNP [15]; and for the treatment of patients with inadequately controlled, moderate-to-severe atopic dermatitis, aged $\geqslant 12$ years in the USA [15] and for adults in the European Union [17] and other countries [21-23].

In the phase 3 LIBERTY ASTHMA QUEST study (NCT02414854), dupilumab $200 \mathrm{mg}$ and $300 \mathrm{mg}$ every 2 weeks versus matched-volume placebo reduced annualised severe exacerbation rates and improved pre-bronchodilator $\mathrm{FEV}_{1}$, improved asthma control, asthma symptoms and quality-of-life measures, and was generally well tolerated in patients with uncontrolled, moderate-to-severe asthma aged $\geqslant 12$ years [19]. The greatest improvements with dupilumab in the phase 3 trial were observed in patients with elevated blood eosinophils or $F_{\mathrm{eNO}}$ at baseline [19].

This article presents further pre-specified and post hoc analyses from the asthma phase 3 LIBERTY ASTHMA QUEST study that extend the primary study results published by CASTRO et al. [19], assessing the effect of dupilumab on lung function. We analyse additional lung function parameters to look in depth at the impact of dupilumab treatment on small airways and the change in lung function (post-bronchodilator $\mathrm{FEV}_{1}$ ) over time in the overall LIBERTY ASTHMA QUEST population and in subgroups of patients with evidence of type 2 inflammation, as reflected by elevated levels of blood eosinophils and $F_{\mathrm{eNO}}$ at baseline.

\section{Methods}

\section{Study design and patients}

Detailed descriptions of the study design, inclusion and exclusion criteria and methodology have been reported previously $[19,24]$. Briefly, LIBERTY ASTHMA QUEST was a global phase 3, multinational, randomised, double-blind, placebo-controlled, parallel-group trial (NCT02414854) in patients with

Affiliations: ${ }^{1}$ Washington University School of Medicine, St Louis, MO, USA. ${ }^{2}$ LungenClinic Grosshansdorf and Christian Albrechts University, members of the German Center for Lung Research (DZL), Kiel, Germany. ${ }^{3}$ David Geffen School of Medicine at UCLA, Los Angeles, CA, USA. ${ }^{4}$ NIHR Oxford Biomedical Research Centre, University of Oxford, Oxford, UK. ${ }^{5}$ Campbelltown Hospital, Campbelltown, NSW, Australia. ${ }^{6}$ Western Sydney University, Sydney, NSW, Australia. ${ }^{7}$ Dept of Respiratory Medicine and Allergology, Kindai University Faculty of Medicine, Osakasayama, Japan. ${ }^{8}$ Sanofi, Bridgewater, NJ, USA. ${ }^{9}$ Sanofi, Cambridge, MA, USA. ${ }^{10}$ Regeneron Pharmaceuticals, Inc., Tarrytown, NY, USA.

Correspondence: Mario Castro, Washington University School of Medicine, Campus Box 8052, 660 S. Euclid Ave, St Louis, MO 63110-1093, USA. E-mail: mcastro2akumc.edu 
uncontrolled, moderate-to-severe asthma who were receiving continuous treatment with medium-to-high doses of ICS plus one or two additional asthma medications. Patients were enrolled in the study without requirement of minimal levels of any type 2 biomarker such as blood eosinophils, serum total immunoglobulin $\mathrm{E}$ or $F_{\mathrm{eNO}}$. Following a 4 -week screening period $( \pm 1$ week), eligible patients were randomised in a 2:2:1:1 ratio to receive 52 weeks of add-on treatment with subcutaneous injections of dupilumab $200 \mathrm{mg}$ (400 mg loading dose) or $300 \mathrm{mg}$ (600 mg loading dose) every 2 weeks or matched-volume placebo.

The study was sponsored by Sanofi and Regeneron Pharmaceuticals. Trial data were collected by the study investigators and analysed by the sponsors. The trial was conducted in accordance with the Declaration of Helsinki and International Conference on Harmonization Good Clinical Practice guidelines. The appropriate institutional review boards and ethics committees approved the trial procedures and documentation, and written informed consent was obtained from all patients (or their legal guardians) before participation.

This paper contains pre-specified and post hoc analyses of outcome measures in the overall intention-to-treat (ITT) population as well as the following "type 2-high" subgroups defined as patients with $\geqslant 150$ eosinophils $\mu \mathrm{L}^{-1}$ at baseline; patients with $\geqslant 300$ eosinophils. $\mu \mathrm{L}^{-1}$ at baseline; patients with $\geqslant 25 \mathrm{ppb} F_{\mathrm{eNO}}$ at baseline; and patients with elevation of both blood eosinophils ( $\geqslant 150$ eosinophils. $\mu \mathrm{L}^{-1}$ ) and $F_{\mathrm{eNO}}(\geqslant 25 \mathrm{ppb})$ at baseline.

\section{Outcomes}

The following pre-specified lung function parameters were assessed at time points up to week 52: change from baseline in pre-bronchodilator $\mathrm{FEV}_{1}$; change from baseline in pre-bronchodilator forced vital capacity (FVC); change from baseline in forced expiratory flow at $25-75 \%$ of $\mathrm{FVC}\left(\mathrm{FEF}_{25-75 \%}\right)$; and change from baseline in the ratio of pre-bronchodilator $\mathrm{FEV}_{1} / \mathrm{FVC}$ ratio. In addition, the slope of change in post-bronchodilator $\mathrm{FEV}_{1}$ was assessed from week 4 to week 52. Change in post-bronchodilator $\mathrm{FEV}_{1}$, the number of patients who achieved an improvement in pre-bronchodilator $\mathrm{FEV}_{1}$ of $\geqslant 200 \mathrm{~mL}$ during treatment and all subgroup analyses were assessed post hoc.

\section{Statistical analysis}

Change from baseline analyses in continuous variables (pre- and post-bronchodilator $\mathrm{FEV}_{1}$, FVC, pre-bronchodilator $\mathrm{FEV}_{1} / \mathrm{FVC}$ ratio and $\mathrm{FEF}_{25-75 \%}$ ) were reported as least-square (LS) mean values and analysed using mixed-effects models with repeated-measures (MMRM). The assigned study treatment arm, patient age, sex, height, geographic region, baseline blood eosinophil strata, baseline dose of ICS, visit, treatment-by-visit, corresponding baseline value of lung function measure and baseline-by-visit interaction were included as covariates. The MMRM included changes from baseline values in lung function variables during treatment from week 2 to week 52 as response variables.

The estimated rate of change in post-bronchodilator $\mathrm{FEV}_{1}$ (post-bronchodilator $\mathrm{FEV}_{1}$ slope) after week 4 was analysed using MMRM, with repeated post-bronchodilator $\mathrm{FEV}_{1}$ as the outcome, and treatment arm, age, sex, height, geographic region, baseline blood eosinophil strata, baseline dose of ICS, time since randomisation, treatment-by-time and baseline post-bronchodilator $\mathrm{FEV}_{1}$ included as covariates.

\section{Results}

\section{Baseline characteristics}

The ITT population of the LIBERTY ASTHMA QUEST trial comprised 1902 patients. As reported previously, the baseline characteristics of the ITT population were similar across the four treatment groups (table 1).

\section{Pre-bronchodilator FEV}

In the overall ITT population, the LS mean change from baseline to week 52 in pre-bronchodilator $\mathrm{FEV}_{1}$ was significantly greater for both doses of dupilumab versus the corresponding matched placebo groups $(\mathrm{p}<0.0001)$, with an LS mean improvement of $0.36 \mathrm{~L}$ in patients treated with dupilumab $200 \mathrm{mg}$ every 2 weeks (LS mean difference versus placebo $0.20 \mathrm{~L}, 95 \%$ CI $0.14-0.25 \mathrm{~L}$ ) and an improvement of $0.35 \mathrm{~L}$ in patients treated with $300 \mathrm{mg}$ every 2 weeks (LS mean difference versus placebo $0.13 \mathrm{~L}, 95 \% \mathrm{CI}$ 0.08-0.19 L). Improvements in pre-bronchodilator $\mathrm{FEV}_{1}$ among patients on dupilumab were rapid and sustained, with substantial changes evident after 2 weeks of treatment, and peak improvements maintained through to week 52 (figure 1a and supplementary table S1). Type 2-high patients, with higher baseline levels of blood eosinophils and/or $F_{\mathrm{eNO}}$, achieved greater benefit with dupilumab treatment versus placebo compared with the ITT population, with patients with both $\geqslant 150$ eosinophils. $\mu \mathrm{L}^{-1}$ and $\geqslant 25 \mathrm{ppb} F_{\mathrm{eNO}}$ at baseline showing an LS mean difference versus placebo of $0.33 \mathrm{~L}$ (95\% CI $0.24-0.43 \mathrm{~L})$ and $0.26 \mathrm{~L}$ (95\% CI 


\section{TABLE 1 Baseline patient demographic and clinical characteristics}

\begin{tabular}{|c|c|c|c|c|c|}
\hline & Placebo & $\begin{array}{l}\text { Dupilumab } 200 \mathrm{mg} \\
\text { every } 2 \text { weeks }\end{array}$ & Placebo & $\begin{array}{l}\text { Dupilumab } 300 \mathrm{mg} \\
\text { every } 2 \text { weeks }\end{array}$ & Overall population \\
\hline Subjects & 317 & 631 & 321 & 633 & 1902 \\
\hline Female & $198(62.5)$ & $387(61.3)$ & $218(67.9)$ & $394(62.2)$ & $1197(62.9)$ \\
\hline $\mathrm{BMI} \mathbf{k g} \cdot \mathrm{m}^{-2}$ & $29.76 \pm 7.25$ & $29.05 \pm 6.52$ & $29.21 \pm 6.95$ & $29.07 \pm 6.68$ & $29.20 \pm 6.77$ \\
\hline Pre-bronchodilator FEV $\mathrm{L}_{1} \mathrm{~L}$ & $1.76 \pm 0.61$ & $1.78 \pm 0.62$ & $1.75 \pm 0.57$ & $1.78 \pm 0.60$ & $1.78 \pm 0.60$ \\
\hline Exacerbations in past year & $2.07 \pm 1.58$ & $2.07 \pm 2.66$ & $2.31 \pm 2.07$ & $2.02 \pm 1.86$ & $2.09 \pm 2.15$ \\
\hline High-dose ICS use & 172 (54.3) & $317(50.2)$ & $167(52.0)$ & $323(51.0)$ & $979(51.5)$ \\
\hline ACQ $-5^{\#}$ score & $2.71 \pm 0.73$ & $2.76 \pm 0.80$ & $2.77 \pm 0.77$ & $2.77 \pm 0.76$ & $2.76 \pm 0.77$ \\
\hline \multicolumn{6}{|l|}{ Biomarker levels } \\
\hline Blood eosinophil count cells $\mu \mathrm{L}^{-1}$ & $370 \pm 338$ & $349 \pm 345$ & $391 \pm 419$ & $351 \pm 369$ & $360 \pm 366$ \\
\hline$F_{\mathrm{eNO}} \mathrm{ppb}$ & $34.47 \pm 28.54$ & $34.45 \pm 34.91$ & $38.39 \pm 38.00$ & $34.01 \pm 29.74$ & $34.97 \pm 32.85$ \\
\hline
\end{tabular}

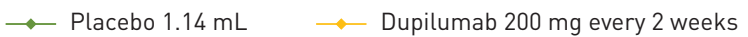

a)

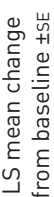

$$
\left.\begin{array}{l}
0.6 \\
0.5 \\
0.4 \\
0.3 \\
0.2 \\
0.1 \\
0
\end{array}\right]
$$

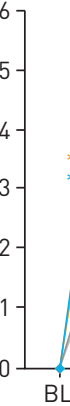

Subjects $\mathrm{n}$

Placebo $1.14 \mathrm{~mL}$

Dupilumab $200 \mathrm{mg}$

Placebo $2 \mathrm{~mL}$

Dupilumab $300 \mathrm{mg}$

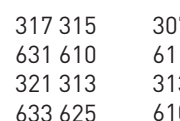

$633625 \quad 610$

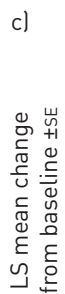

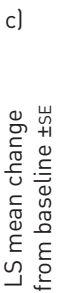

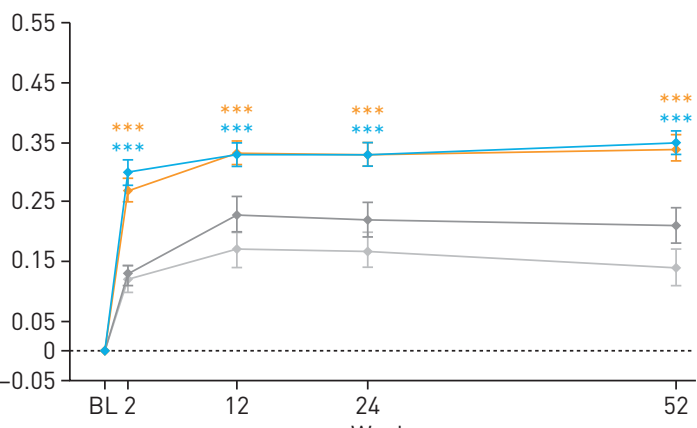

Subjects $n$

Placebo $1.14 \mathrm{~mL}$

Dupilumab $200 \mathrm{mg}$

Placebo $2 \mathrm{~mL}$

Dupilumab $300 \mathrm{mg}$

317315

631610

321313

633625

307
611
313
610

$$
\text { Week }
$$

300

599

296

596 $\multimap$ Placebo $2 \mathrm{~mL} \quad \longrightarrow$ Dupilumab $300 \mathrm{mg}$ every 2 weeks
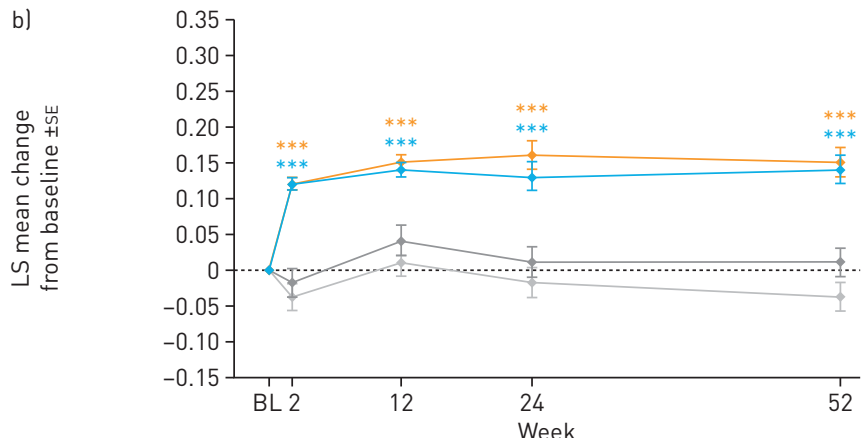

Subjects $\mathrm{n}$

Placebo $1.14 \mathrm{~mL} \quad 317310 \quad 305 \quad 302 \quad 239$

Dupilumab $200 \mathrm{mg} \quad 631609 \quad 610 \quad 599 \quad 499$

$\begin{array}{lllll}\text { Placebo } 2 \mathrm{~mL} & 321311 & 313 & 302 & 255\end{array}$

Dupilumab $300 \mathrm{mg} \quad 633617 \quad 612 \quad 601 \quad 494$

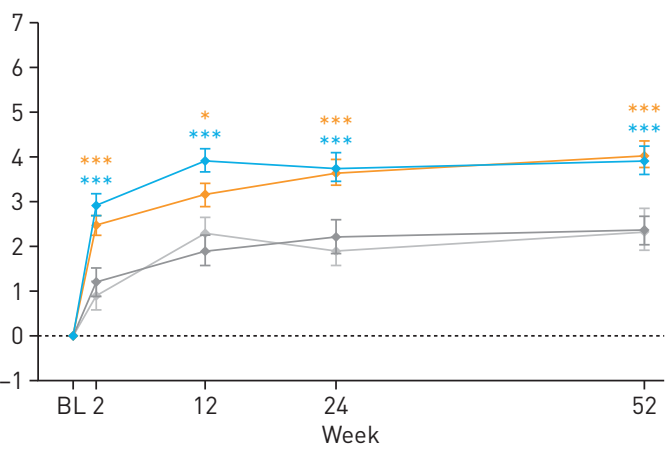

Subjects $\mathrm{n}$

Plocts $1.14 \mathrm{~mL}$

Dupilumab $200 \mathrm{mg} \quad 631610$

Placebo $2 \mathrm{~mL}$

321313

Dupilumab $300 \mathrm{mg} \quad 633625 \quad 610$

$\begin{array}{lll}307 & 300 & 240 \\ 611 & 599 & 477 \\ 313 & 296 & 250 \\ 610 & 596 & 488\end{array}$

FIGURE 1 Least-square (LS) mean change from baseline (BL) over the 52-week treatment period in the intention-to-treat population in a) pre-bronchodilator forced expiratory volume in $1 \mathrm{~s}\left(\mathrm{FEV}_{1}\right)$; b) post-bronchodilator $\mathrm{FEV}_{1}$; c) forced vital capacity $\left.(\mathrm{FVC}) ; \mathrm{d}\right) \mathrm{FEV} \mathrm{F}_{1} / \mathrm{FVC}$ ratio. ${ }^{*}$ : $\mathrm{p}<0.05$, $* * *: p<0.001$ 
0.17-0.35 L) at week 52 when treated with dupilumab $200 \mathrm{mg}$ or $300 \mathrm{mg}$ every 2 weeks, respectively (figure $2 \mathrm{a}-\mathrm{d}$ and supplementary table $\mathrm{S} 1$ ).

\section{Post-bronchodilator FEV 1}

In the overall ITT population, the LS mean change from baseline to week 52 in post-bronchodilator $\mathrm{FEV}_{1}$ was significantly greater for dupilumab versus matched placebo (LS mean difference versus placebo $0.19 \mathrm{~L}$ (95\% CI $0.14-0.24 \mathrm{~L}$ ) for dupilumab $200 \mathrm{mg}$ every 2 weeks, and $0.13 \mathrm{~L}$ (95\% CI $0.08-0.18 \mathrm{~L}$ ) for dupilumab $300 \mathrm{mg}$ every 2 weeks; both $\mathrm{p}<0.0001)$. Improvements in patients on dupilumab were observed after 2 weeks of treatment and maintained through to week 52 (figure $1 \mathrm{~b}$ and supplementary table S2). Significant improvements in post-bronchodilator $\mathrm{FEV}_{1}$ were also seen in type 2-high subgroups of patients, with greater improvements versus placebo observed in all type 2-high subgroups when compared with improvements in the ITT population (figure 3a-d and supplementary table S2).

\section{Post-bronchodilator FEV 1 slope from week 4 to week 52}

In the ITT population, rate of change from baseline over time in post-bronchodilator $\mathrm{FEV}_{1}\left(\mathrm{FEV}_{1}\right.$ slope) during the 52-week treatment period after week 4 was significantly different compared with placebo, with an estimated slope \pm SE of $0.00 \pm 0.01 \mathrm{~L} \cdot y e a r^{-1}$ for both dupilumab doses, and an estimated negative slope of $-0.04 \pm 0.02 \mathrm{~L} \cdot \mathrm{year}^{-1}$ for both matched placebo groups. The LS mean difference in the rate of change from baseline over time in post-bronchodilator $\mathrm{FEV}_{1}$ versus matched placebo was $0.04 \mathrm{~L} \cdot \mathrm{year}^{-1}$ (95\% CI 0.00-0.08 L.year ${ }^{-1}$; $\mathrm{p}=0.04$ ) for both $200 \mathrm{mg}$ and $300 \mathrm{mg}$ dupilumab every 2 weeks (table 2). Although the differences versus placebo for the type 2-high subgroups of patients were not statistically significant, there
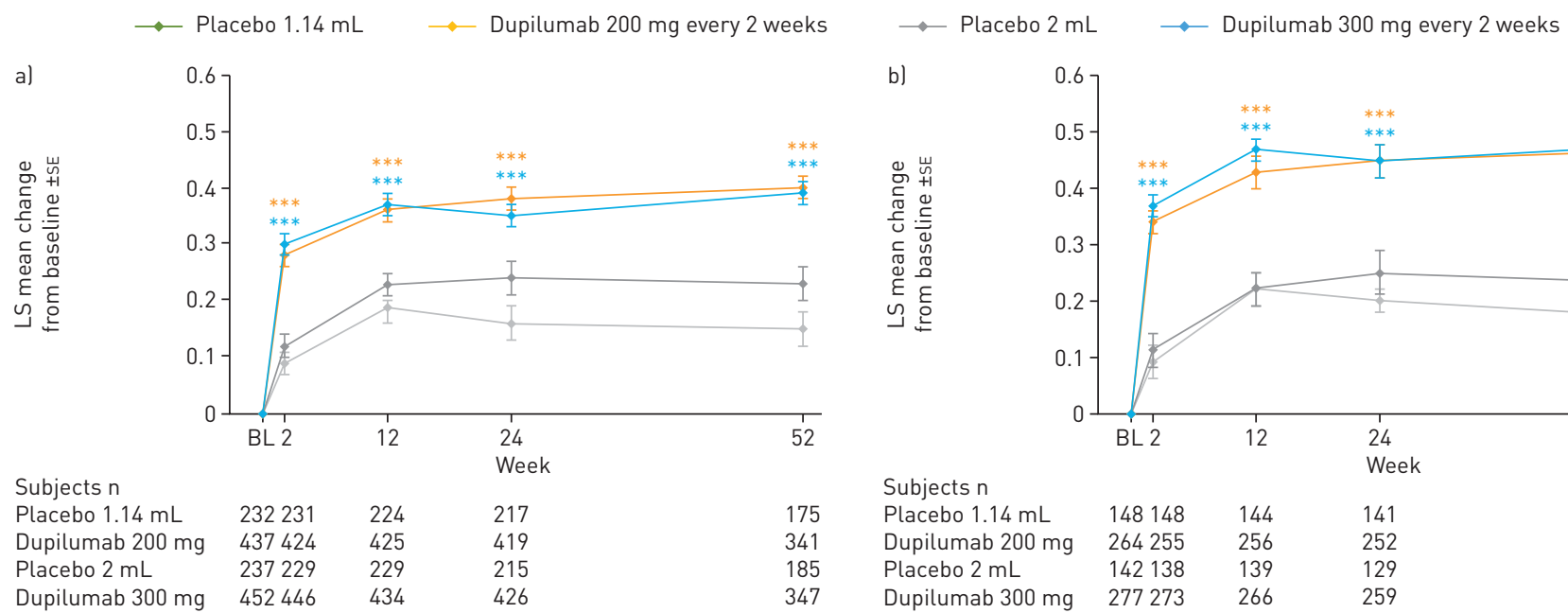

c)
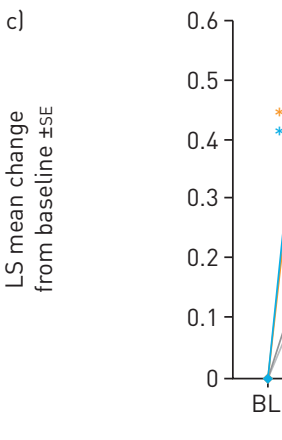

Subjects $n$

Placebo $1.14 \mathrm{~mL} \quad 162161$

Dupilumab $200 \mathrm{mg} \quad 299291$

Placebo $2 \mathrm{~mL}$

172167

Dupilumab $300 \mathrm{mg}$

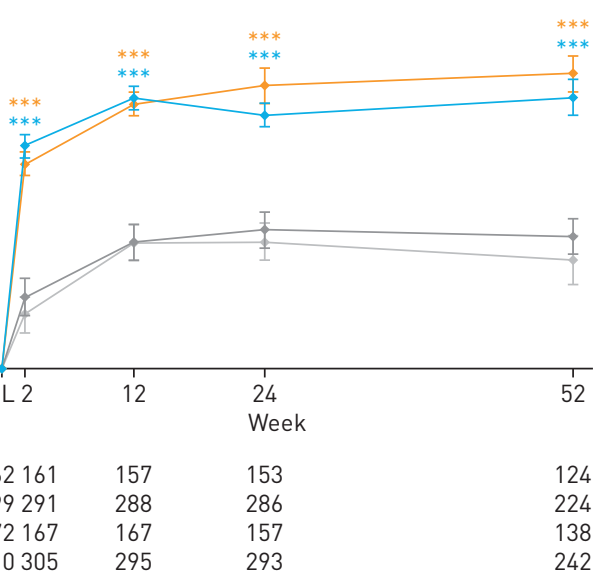

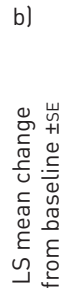

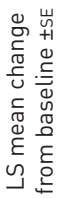

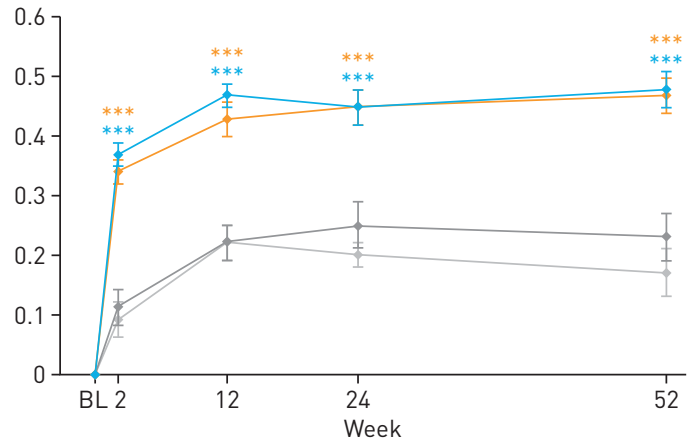

Subjects $n$

$\begin{array}{lllll}\text { Placebo } 1.14 \mathrm{~mL} & 148148 & 144 & 141 & 113\end{array}$

Dupilumab $200 \mathrm{mg} \quad 264255 \quad 256 \quad 252 \quad 206$

Placebo $2 \mathrm{~mL}$

Dupilumab $300 \mathrm{mg} \quad 277273 \quad 266 \quad 259$

d)

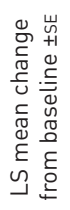

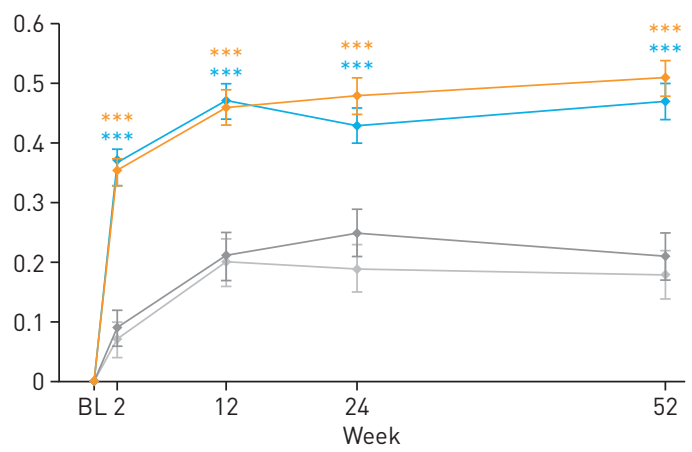

Subjects $n$

$\begin{array}{lllll}\text { Placebo } 1.14 \mathrm{~mL} & 134134 & 130 & 126 & 101\end{array}$

$\begin{array}{llll}\text { Dupilumab } 200 \mathrm{mg} & 248240 & 238 & 238\end{array}$

Placebo $2 \mathrm{~mL}-142137$

Dupilumab $300 \mathrm{mg} \quad 258253 \quad 245 \quad 244 \quad 203$

FIGURE 2 Least-square (LS) mean change from baseline (BL) in pre-bronchodilator forced expiratory volume in $1 \mathrm{~s}$ over the 52 -week treatment period in patients with a) $\geqslant 150$ eosinophils. $\mu \mathrm{L}^{-1}$ at $\left.\mathrm{BL} ; \mathrm{b}\right) \geqslant 300$ eosinophils. $\mu \mathrm{L}^{-1}$ at $\left.\mathrm{BL} ; \mathrm{c}\right) \geqslant 25 \mathrm{ppb}$ fractional exhaled nitric oxide $\left(F_{\mathrm{eNo}}\right)$ at $\mathrm{BL}$; and d) both $\geqslant 150$ eosinophils $\mu \mathrm{L}^{-1}$ and $\geqslant 25 \mathrm{ppb} F_{\mathrm{eNO}}$ at BL. ${ }^{* * *}$ : $\mathrm{p}<0.001$. 

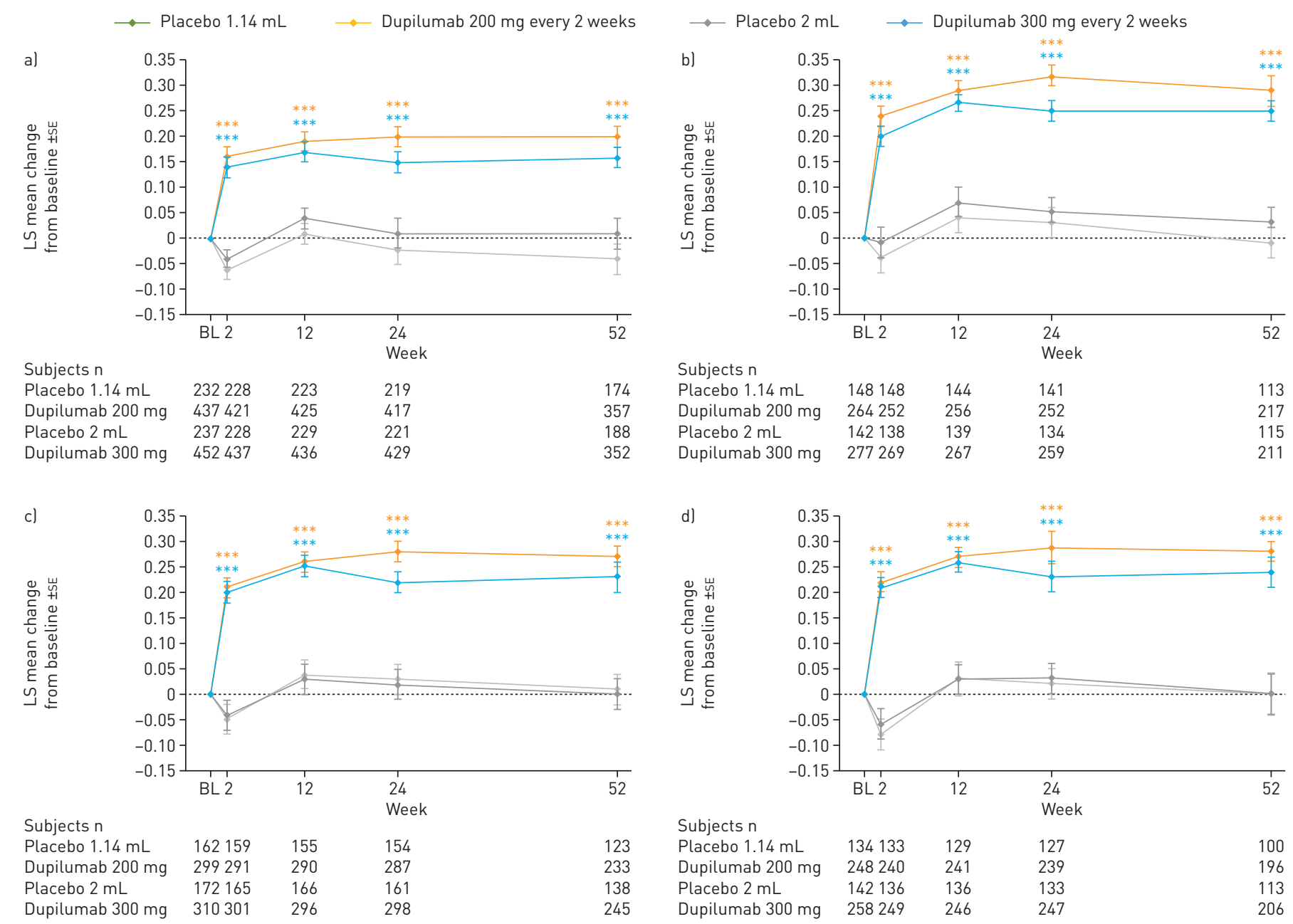

FIGURE 3 Least-square (LS) mean change from baseline (BL) in post-bronchodilator forced expiratory volume in $1 \mathrm{~s}$ over the 52 -week treatment period in patients with a) $\geqslant 150$ eosinophils. $\mu \mathrm{L}^{-1}$ at $\left.\mathrm{BL} ; \mathrm{b}\right) \geqslant 300$ eosinophils. $\mu \mathrm{L}^{-1}$ at $\left.\mathrm{BL} ; \mathrm{c}\right) \geqslant 25 \mathrm{ppb}$ fractional exhaled nitric oxide $\left(F_{\mathrm{eNO}}\right)$ at $\mathrm{BL}$; d) both $\geqslant 150$ eosinophils $\mu \mathrm{L}^{-1}$ and $\geqslant 25 \mathrm{ppb} F_{\mathrm{eNO}}$ at BL. ${ }^{* * *}$ : $\mathrm{p}<0.001$.

was a similar numerical difference versus placebo for most comparisons to that seen with the overall ITT population (table 2).

\section{Pre-bronchodilator FVC}

The LS mean change from baseline in FVC at week 52 in the ITT population was significantly greater in patients who received dupilumab compared with placebo $(\mathrm{p}<0.0001)$ (figure $1 \mathrm{c}$ and supplementary table $\mathrm{S} 3$ ). Improvements were rapid and sustained across the 52 weeks of treatment. Patients with both $\geqslant 150$ blood eosinophils $\mu \mathrm{L}^{-1}$ and $F_{\mathrm{eNO}} \geqslant 25 \mathrm{ppb}$ at baseline experienced the greatest improvement versus placebo in FVC, although a greater improvement versus placebo in FVC at week 52 was seen in all the type 2-high subgroups analysed compared with the overall population (figure 4a-d and supplementary table S3). Improvements in FVC versus placebo in these patient subgroups were significant from the earliest time point $(\mathrm{p}<0.01$ in both doses for all subgroups).

\section{Pre-bronchodilator FEV $1 / F V C$ ratio}

In line with the observed improvements in both $\mathrm{FEV}_{1}$ and $\mathrm{FVC}$, the ratio of $\mathrm{FEV}_{1} / \mathrm{FVC}$ significantly improved $(\mathrm{p}<0.001)$ in both dupilumab dose groups compared with respective matched placebo in the overall study population at week 52 (figure 1d and supplementary table S4). Greater improvements at week 52 in the $\mathrm{FEV}_{1} / \mathrm{FVC}$ ratio were observed with both dupilumab dose groups versus matched placebo $(\mathrm{p}<0.01)$ in patients with elevated baseline blood eosinophils or $F_{\mathrm{eNO}}$ (or both elevated eosinophils and $F_{\mathrm{eNO}}$ ) (figure 5a-d and supplementary table S4). As would be expected from the early observed improvement in both $\mathrm{FEV}_{1}$ and FVC, significant improvements $(\mathrm{p}<0.05)$ in the $\mathrm{FEV}_{1} / \mathrm{FVC}$ ratio with dupilumab $200 \mathrm{mg}$ or $300 \mathrm{mg}$ every 2 weeks relative to matched placebo occurred from week 2 and were sustained throughout 
TABLE 2 Post-bronchodilator forced expiratory volume in $1 \mathrm{~s}\left(\mathrm{FEV}_{1}\right)$ slope during the 52 -week treatment period (after week 4) across different patient subgroups

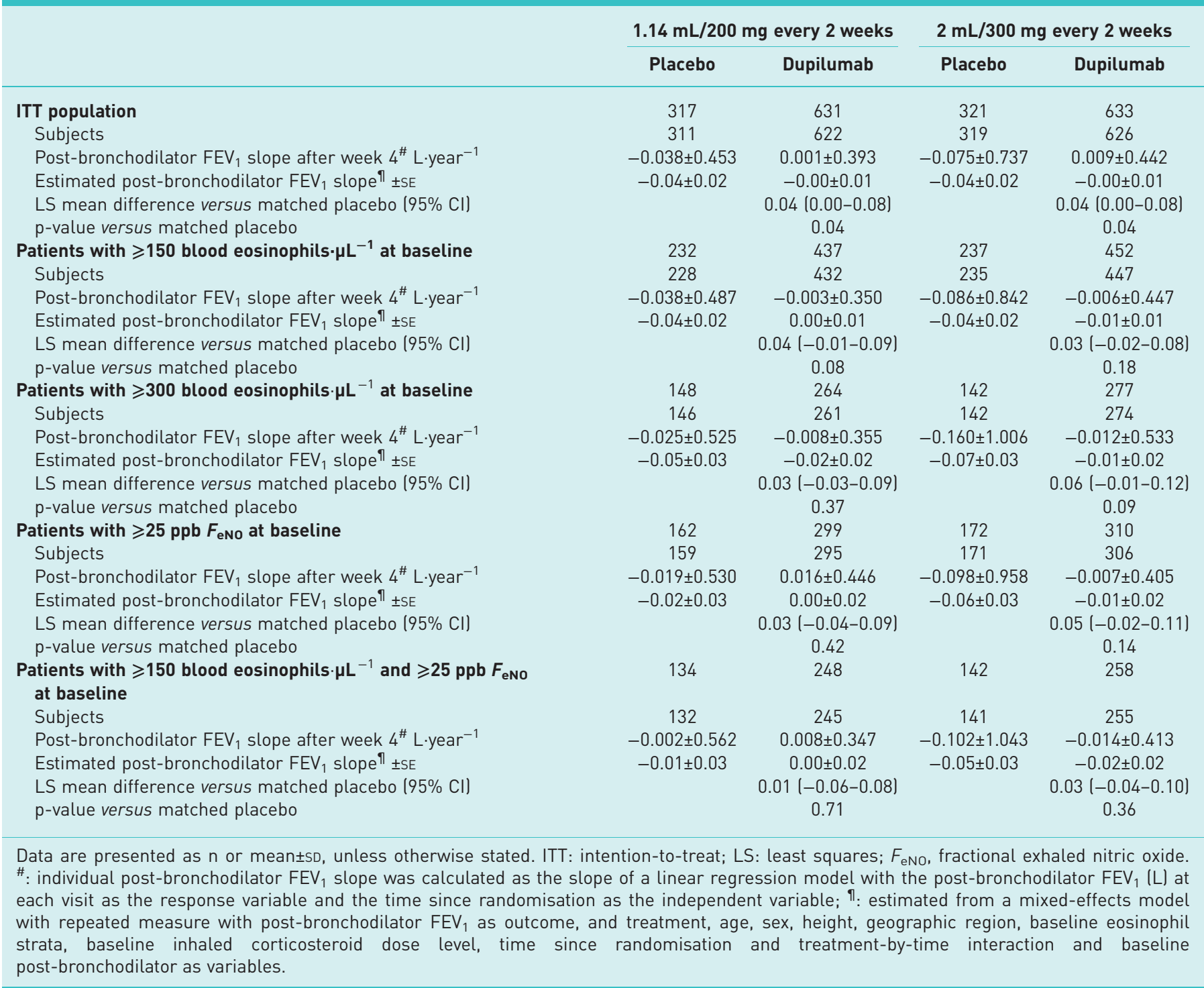

the treatment period to week 52 in the ITT population and in patients with elevated type 2 biomarkers (figures $1 \mathrm{~d}$ and $5 \mathrm{a}-\mathrm{d}$ and supplementary table $\mathrm{S} 4$ ).

Pre-bronchodilator FEF $_{25-75 \%}$

$\mathrm{FEF}_{25-75 \%}$ was significantly improved in both the dupilumab $200 \mathrm{mg}$ and $300 \mathrm{mg}$ every 2 weeks dose groups compared with matched-volume placebo throughout the treatment period in the overall population and the type 2-high subgroups analysed $(\mathrm{p}<0.01)$ (supplementary table S5). The largest improvements in $\mathrm{FEF}_{25-75 \%}$ with dupilumab versus placebo were seen in those type 2-high patients with elevated baseline eosinophils and/or $F_{\text {eNO }}$ (supplementary table S5).

Patients with $\geqslant 200 \mathrm{~mL}$ improvement in pre-bronchodilator FEV,

The proportion of patients who attained an improvement of $\geqslant 200 \mathrm{~mL}$ in pre-bronchodilator $\mathrm{FEV}_{1}$ during the 52-week treatment period in the overall population and each of the type 2-high biomarker subgroups is summarised in supplementary table S6. In the overall population, the proportion of patients who achieved $\mathrm{a} \geqslant 200 \mathrm{~mL}$ improvement in pre-bronchodilator $\mathrm{FEV}_{1}$ by week 52 of treatment was higher in each of the dupilumab treatment groups $(50.5 \%$ and $54.5 \%$ for the $200 \mathrm{mg}$ and $300 \mathrm{mg}$ every 2 weeks dose groups, respectively) than the matched placebo groups $(37.1 \%$ and $44.0 \%$ for the respective placebo 

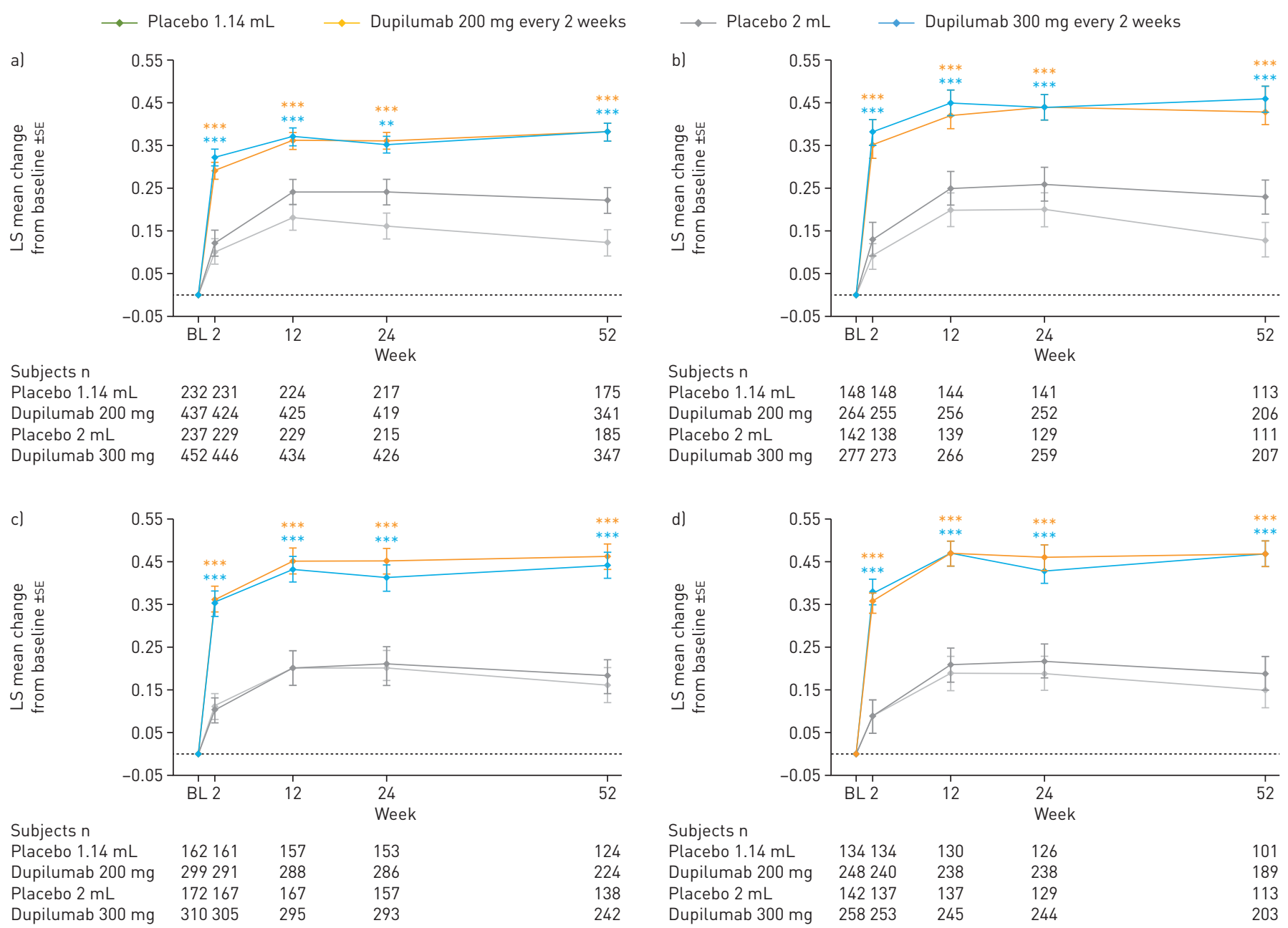

FIGURE 4 Least-square (LS) mean change from baseline (BL) in pre-bronchodilator forced vital capacity over the 52-week treatment period in patients with a) $\geqslant 150$ eosinophils. $\mu \mathrm{L}^{-1}$ at $\left.\mathrm{BL} ; \mathrm{b}\right) \geqslant 300$ eosinophils. $\mu \mathrm{L}^{-1}$ at $\left.\mathrm{BL} ; \mathrm{c}\right) \geqslant 25 \mathrm{ppb}$ fractional exhaled nitric oxide $\left(F_{\mathrm{eNo}}\right)$ at $\mathrm{BL} ; \mathrm{d}$ ) both $\geqslant 150$ eosinophils $\mu \mathrm{L}^{-1}$ and $\geqslant 25 \mathrm{ppb} F_{\mathrm{eNO}}$ at BL. ${ }^{* *}: \mathrm{p}<0.01,{ }^{* * *}: \mathrm{p}<0.001$.

groups). A numerically higher proportion of patients achieved a $\geqslant 200 \mathrm{~mL}$ improvement in pre-bronchodilator $\mathrm{FEV}_{1}$ by week 52 in patients in the dupilumab treatment groups who had both elevated baseline blood eosinophils and elevated $F_{\mathrm{eNO}}(70.4 \%$ and $66.0 \%$ in the dupilumab $200 \mathrm{mg}$ and $300 \mathrm{mg}$ every 2 weeks groups, respectively, compared with $43.6 \%$ and $43.4 \%$ in the matched placebo groups), not assessed for statistical significance.

\section{Discussion}

This analysis of pre-specified secondary and post hoc results from patients with uncontrolled, moderate-to-severe asthma enrolled in the LIBERTY ASTHMA QUEST phase 3 trial showed that lung function across large and small airway outcome measures $\left(\mathrm{FEV}_{1}, \mathrm{FVC}, \mathrm{FEV}_{1} / \mathrm{FVC}\right.$ and $\left.\mathrm{FEF}_{25-75 \%}\right)$ showed significant improvements for patients treated with dupilumab compared with placebo in the overall ITT population. Improvements in these lung function parameters were rapid (noted at the first assessment time point) and sustained over a 52-week treatment period. A higher number of patients treated with dupilumab achieved a $\geqslant 200 \mathrm{~mL}$ improvement in pre-bronchodilator $\mathrm{FEV}_{1}$. A minimal clinically important difference for $\mathrm{FEV}_{1}$ has not been established for asthma, but it is thought that an improvement of $100-200 \mathrm{~mL}$ would be clinically important $[25,26]$.

These data support previously reported findings that add-on dupilumab treatment reduces the number of severe asthma exacerbations and improves lung function compared with placebo, particularly in patients with higher baseline levels of blood eosinophils or $F_{\mathrm{eNO}}[18,19]$.

Greater dupilumab efficacy was observed in patients with elevated baseline levels of either blood eosinophils or $F_{\mathrm{eNO}}$, both biomarkers of type 2 inflammation. A growing body of data suggests that 

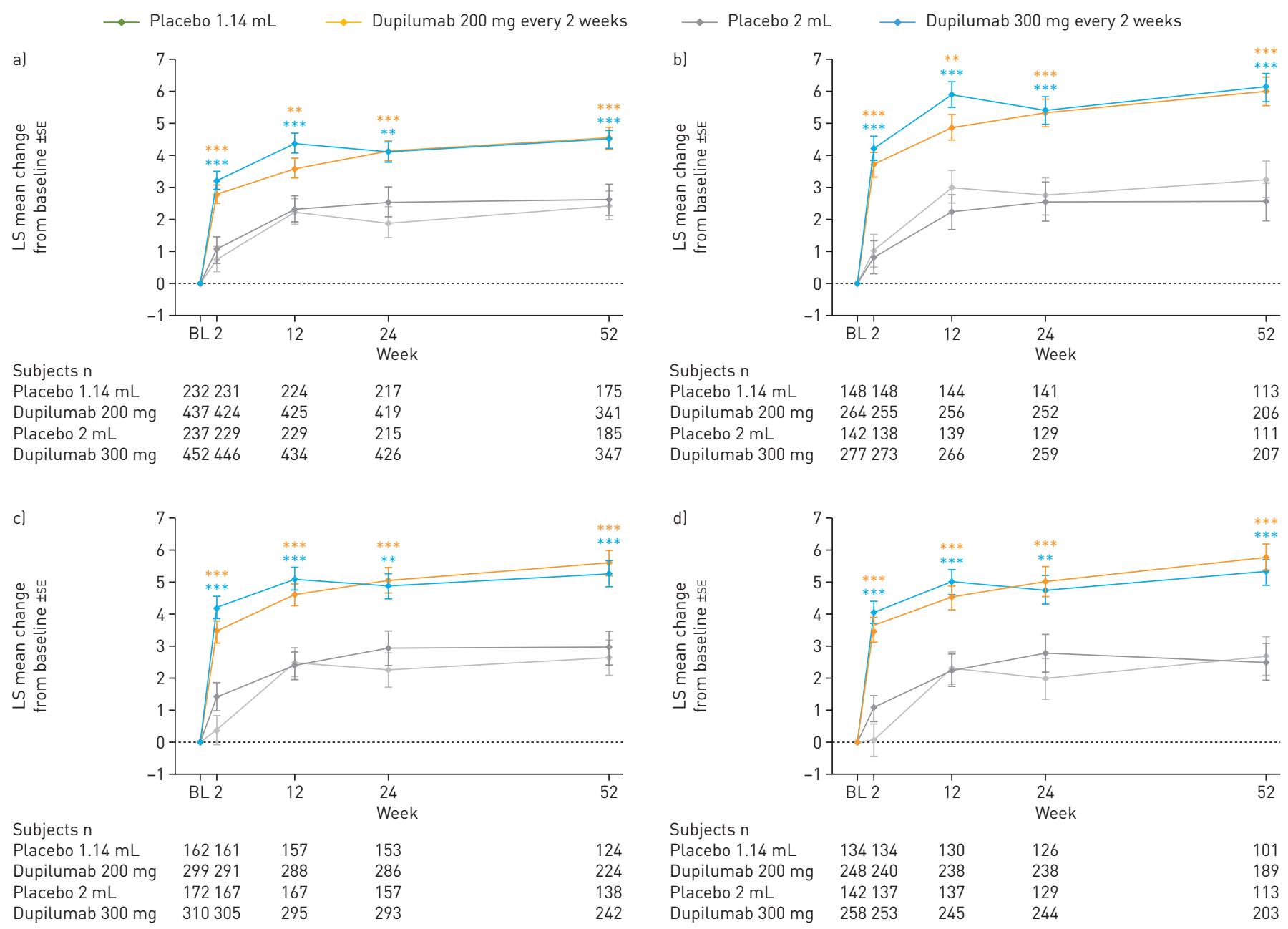

FIGURE 5 Least-square (LS) mean change from baseline (BL) in pre-bronchodilator forced expiratory volume in $1 \mathrm{~s} /$ forced vital capacity ratio over the 52 -week treatment period in patients with al $\geqslant 150$ eosinophils. $\mu \mathrm{L}^{-1}$ at $\left.\mathrm{BL} ; \mathrm{b}\right) \geqslant 300$ eosinophils. $\mu \mathrm{L}^{-1}$ at $\left.\mathrm{BL} ; \mathrm{c}\right) \geqslant 25 \mathrm{ppb}$ fractional exhaled nitric oxide $\left(F_{\mathrm{eNO}}\right)$ at $\left.\mathrm{BL} ; \mathrm{d}\right)$ both $\geqslant 150$ eosinophils $\mu \mathrm{L}^{-1}$ and $\geqslant 25 \mathrm{ppb} F_{\mathrm{eNO}}$ at $\mathrm{BL} .{ }^{*}: \mathrm{p}<0.05,{ }^{* *}: \mathrm{p}<0.01,{ }^{* * *}: \mathrm{p}<0.001$.

blood eosinophils and $F_{\mathrm{eNO}}$ are good markers of type 2 inflammation in asthmatic airways, and that blood eosinophilia reflects airway eosinophilia in asthma $[27,28]$. IL-13 plays a predominant role in the production of $F_{\mathrm{eNO}}$ by upregulating epithelial cell inducible nitric oxide synthase [10]. Taken together, these data are in line with the mechanism of action of dupilumab, which provides dual blockade targeting both IL-4 and IL-13 signalling pathways. The positive effect seen across several lung function parameters in patients with high baseline levels of either blood eosinophils or $F_{\mathrm{eNO}}$ or both supports the broad efficacy of dupilumab.

Post-bronchodilator airway function correlates with aspects of airway remodelling $[29,30]$. In the overall QUEST treatment population, there was no observed decline in lung function with dupilumab treatment as measured by post-bronchodilator $\mathrm{FEV}_{1}$ slope from week 4 to week 52 . In contrast, the placebo groups experienced an estimated $40 \mathrm{~mL} \cdot \mathrm{year}^{-1}$ decline in $\mathrm{FEV}_{1}$, a rate of decline reported/expected in patients with moderate-to-severe uncontrolled asthma [31]. Mucus plugging is a potential mechanism for airflow obstruction and lung function decline in severe asthma, furthered by involvement of type 2 inflammation of the airways [32]. Reversal of the mucus plugging by dupilumab could be a potential explanation of why the expected lung function decline in these patients was not seen on treatment. Lung function decline in both placebo and dupilumab-treated patients was greatest in the subgroup of patients with $\geqslant 300$ eosinophils $\mu \mathrm{L}^{-1}$ at baseline, indicating a role of type 2 inflammation in contributing to the pathophysiology of lung function decline. A study with a longer-term observation period using imaging will be required to confirm this finding.

As reported in detail previously [20], dupilumab treatment was well tolerated (data not shown). The proportion of patients with serious treatment-emergent adverse events related to dupilumab was low (8.2\%) and similar to that reported with combined placebo (8.4\%). 
A potential limitation of these findings was our reliance on spirometry $\left(\mathrm{FEF}_{25-75 \%}\right)$ to assess small airways function. This technique is regarded by some to be less than optimal, as measurements can be influenced by large airway obstruction [33]. While a reliable, non-invasive index for diagnosis and monitoring of small airways disease remains elusive, other techniques such as imaging with computed tomography or magnetic resonance imaging, plethysmography and impulse oscillometry have proven valuable in some studies [34].

In conclusion, these further observations from the phase 3 LIBERTY ASTHMA QUEST trial show that add-on therapy with dupilumab $200 \mathrm{mg}$ or $300 \mathrm{mg}$ every 2 weeks compared with matched placebo significantly improves outcomes across a range of lung function measures, including those of large and small airways and fixed airway obstruction, in patients with uncontrolled, moderate-to-severe asthma. The observed improvements in lung function were rapid and sustained throughout the treatment period. Greater improvements in lung function were observed in patients with higher baseline levels of blood eosinophils and $F_{\mathrm{eNO}}$, markers of type 2 inflammation. The positive effect of dupilumab on lung function and the protective effect against asthma exacerbations should be further investigated long-term to better understand the implications of these benefits.

Support statement: The LIBERTY ASTHMA QUEST trial was sponsored by Sanofi and Regeneron Pharmaceuticals, Inc. Writing and editorial assistance in the development of this manuscript was provided by Adam J. Beech of Excerpta Medica (Amsterdam, the Netherlands), funded by Sanofi Genzyme and Regeneron Pharmaceuticals, Inc. Funding information for this article has been deposited with the Crossref Funder Registry.

Conflict of interest: M. Castro reports grants, personal fees and nonfinancial support from Sanofi, and personal fees from Regeneron Pharmaceuticals, during the conduct of the study; and grants from the American Lung Association, Chiesi, the NIH, Novartis and PCORI, grants and personal fees from AstraZeneca, Boehringer Ingelheim and Sanofi, and personal fees from 4D Pharma, Aviragen Theraputics, Boston Scientific, Elsevier, Genentech, Nuvaira, Teva, Therabron, Theravance Biopharma, Vectura and VIDA Pharma, outside the submitted work. K.F. Rabe reports personal fees from AstraZeneca, Boehringer Ingelheim, Chiesi, Novartis, Sanofi, Sterna Biologicals, Teva and Verona Pharma, outside the submitted work. J. Corren reports grants and nonfinancial support from Sanofi during the conduct of the study. I.D. Pavord reports personal fees and nonfinancial support from Sanofi, and personal fees from Regeneron Pharmaceuticals, during the conduct of the study; and personal fees from Aerocrine AB, Almirall, Circassia, Dey Pharma, Genentech, Knopp Biosciences, Merck, MSD, Novartis, RespiVert and Schering-Plough, personal fees and nonfinancial support from AstraZeneca, Boehringer Ingelheim, GSK, Napp Pharmaceuticals and Teva, and grants, personal fees and nonfinancial support from Chiesi, outside the submitted work. C.H. Katelaris reports grants from Sanofi outside the submitted work. Y. Tohda reports personal fees from Sanofi during the conduct of the study; and personal fees from AstraZeneca and KYORIN Pharmaceutical, outside the submitted work. B. Zhang reports personal fees from Sanofi during the conduct of the study. M.S. Rice reports personal fees from Sanofi during the conduct of the study. J. Maroni reports personal fees from Regeneron Pharmaceuticals during the conduct of the study. P. Rowe reports personal fees from Sanofi during the conduct of the study. G. Pirozzi reports personal fees from Sanofi during the conduct of the study. N. Amin reports personal fees from Regeneron Pharmaceuticals during the conduct of the study. M. Ruddy reports personal fees from Regeneron Pharmaceuticals during the conduct of the study. B. Akinlade reports personal fees from Regeneron Pharmaceuticals during the conduct of the study. N.M.H. Graham reports personal fees from Regeneron Pharmaceuticals during the conduct of the study. A. Teper reports personal fees from Sanofi during the conduct of the study.

\section{References}

1 Bateman ED, Boushey HA, Bousquet J, et al. Can guideline-defined asthma control be achieved? The Gaining Optimal Asthma Control study. Am J Respir Crit Care Med 2004; 170: 836-844.

2 Braido F, Brusselle G, Guastalla D, et al. Determinants and impact of suboptimal asthma control in Europe: the International Cross-Sectional and Longitudinal Assessment on Asthma Control (LIAISON) study. Respir Res 2016; 17: 51 .

3 Hermosa JL, Sánchez CB, Rubio MC, et al. Factors associated with the control of severe asthma. J Asthma 2010; 47: $124-130$.

4 Lange P, Parner J, Vestbo J, et al. A 15-year follow-up study of ventilatory function in adults with asthma. $N$ Engl J Med 1998; 339: 1194-1200.

5 Peters SP, Ferguson G, Deniz Y, et al. Uncontrolled asthma: a review of the prevalence, disease burden and options for treatment. Respir Med 2006; 100: 1139-1151.

6 Peters SP, Jones CA, Haselkorn T, et al. Real-world Evaluation of Asthma Control and Treatment (REACT) findings from a national web-based survey. J Allergy Clin Immunol 2007; 119: 1454-1461.

7 Global Initiative for Asthma (GINA). Global Strategy for Asthma Management and Prevention. http://ginasthma. org/wp-content/uploads/2016/01/GINA_Report_2015_Aug11-1.pdf Date last accessed: May 22, 2019. Date last updated: 2015.

8 Voehringer D, Reese TA, Huang X, et al. Type 2 immunity is controlled by IL-4/IL-13 expression in hematopoietic non-eosinophil cells of the innate immune system. J Exp Med 2006; 203: 1435-1446.

9 Fahy JV. Type 2 inflammation in asthma - present in most, absent in many. Nat Rev Immunol 2015; 15: 57-65.

10 Robinson D, Humbert M, Buhl R, et al. Revisiting type 2-high and type 2-low airway inflammation in asthma: current knowledge and therapeutic implications. Clin Exp Allergy 2017; 47: 161-175.

11 Thomson NC. Novel approaches to the management of noneosinophilic asthma. Ther Adv Respir Dis 2016; 10: $211-234$. 
12 Macdonald LE, Karow M, Stevens S, et al. Precise and in situ genetic humanization of $6 \mathrm{Mb}$ of mouse immunoglobulin genes. Proc Natl Acad Sci USA 2014; 111: 5147-5152.

13 Murphy AJ, Macdonald LE, Stevens S, et al. Mice with megabase humanization of their immunoglobulin genes generate antibodies as efficiently as normal mice. Proc Natl Acad Sci USA 2014; 111: 5153-5158.

14 Gandhi NA, Bennett BL, Graham NM, et al. Targeting key proximal drivers of type 2 inflammation in disease. Nat Rev Drug Discov 2016; 15: 35-50.

15 US Food and Drug Administration. DUPIXENT (dupilumab): Highlights of prescribing information. www. accessdata.fda.gov/drugsatfda_docs/label/2019/761055s014lbl.pdf Date last updated: June 2019. Date last accessed: July 2, 2019.

16 Japan Pharmaceuticals and Medical Devices Agency. DUPIXENT (dupilumab). www.pmda.go.jp/PmdaSearch/ iyakuDetail/ResultDataSetPDF/780069_4490405G1024_1_04 Date last accessed: June 19, 2019.

17 European Medicines Agency. DUPIXENT ${ }^{\circ}$ (dupilumab). http://ec.europa.eu/health/documents/communityregister/2019/20190506144541/anx_144541_en.pdf Date last accessed: June 19, 2019.

18 Wenzel S, Castro M, Corren J, et al. Dupilumab efficacy and safety in adults with uncontrolled persistent asthma despite use of medium-to-high-dose inhaled corticosteroids plus a long-acting $\beta_{2}$ agonist: a randomised double-blind placebo-controlled pivotal phase $2 \mathrm{~b}$ dose-ranging trial. Lancet 2016; 388: 31-44.

19 Castro M, Corren J, Pavord ID, et al. Dupilumab efficacy and safety in moderate-to-severe uncontrolled asthma. N Engl J Med 2018; 378: 2486-2496.

20 Rabe KF, Nair P, Brusselle G, et al. Efficacy and safety of dupilumab in glucocorticoid-dependent severe asthma. N Engl J Med 2018; 378: 2475-2485.

21 Blauvelt $\mathrm{A}$, de Bruin-Weller $\mathrm{M}$, Gooderham $\mathrm{M}$, et al. Long-term management of moderate-to-severe atopic dermatitis with dupilumab and concomitant topical corticosteroids (LIBERTY AD CHRONOS): a 1-year, randomised, double-blinded, placebo-controlled phase 3 trial. Lancet 2017; 389: 2287-2303.

22 Simpson EL, Bieber T, Guttman-Yassky E, et al. Two phase 3 trials of dupilumab versus placebo in atopic dermatitis. N Engl J Med 2016; 375: 2335-2348.

23 Thaçi D, Simpson EL, Beck LA, et al. Efficacy and safety of dupilumab in adults with moderate-to-severe atopic dermatitis inadequately controlled by topical treatments: a randomised, placebo-controlled, dose-ranging phase $2 \mathrm{~b}$ trial. Lancet 2016; 387: 40-52.

24 Busse WW, Maspero JF, Rabe KF, et al. Liberty Asthma QUEST: phase 3 randomized, double-blind, placebo-controlled, parallel-group study to evaluate dupilumab efficacy/safety in patients with uncontrolled, moderate-to-severe asthma. Adv Ther 2018; 35: 737-748.

25 Santanello NC, Zhang J, Seidenberg B, et al. What are minimal important changes for asthma measures in a clinical trial? Eur Respir J 1999; 14: 23-27.

26 Tepper RS, Wise RS, Covar R, et al. Asthma outcomes: pulmonary physiology. J Allergy Clin Immunol 2012; 129: S65-S87.

27 Gao J, Wu F. Association between fractional exhaled nitric oxide, sputum induction and peripheral blood eosinophil in uncontrolled asthma. Allergy Asthma Clin Immunol 2018; 14: 21.

28 Wagener AH, de Nijs SB, Lutter R, et al. External validation of blood eosinophils, FE(NO) and serum periostin as surrogates for sputum eosinophils in asthma. Thorax 2015; 70: 115-120.

29 Chae EJ, Kim TB, Cho YS, et al. Airway measurement for airway remodeling defined by post-bronchodilator FEV1/FVC in asthma: investigation using inspiration-expiration computed tomography. Allergy Asthma Immunol Res 2011; 3: 111-117.

30 Boulet LP. Airway remodeling in asthma: update on mechanisms and therapeutic approaches. Curr Opin Pulm Med 2018; 24: 56-62.

31 Sears MR. Lung function decline in asthma. Eur Respir J 2007; 30: 411-413.

32 Dunican EM, Elicker BM, Gierada DS, et al. Mucus plugs in patients with asthma linked to eosinophilia and airflow obstruction. J Clin Invest 2018; 128: 997-1009.

33 Carr TF, Altisheh R, Zitt M. Small airways disease and severe asthma. World Allergy Organ J 2017; 10: 20.

34 Braido F, Scichilone N, Lavorini F, et al. Manifesto on small airway involvement and management in asthma and chronic obstructive pulmonary disease: an Interasma (Global Asthma Association - GAA) and World Allergy Organization (WAO) document endorsed by Allergic Rhinitis and its Impact on Asthma (ARIA) and Global Allergy and Asthma European Network (GA ${ }^{2}$ LEN). World Allergy Organ J 2016; 9: 37. 